Section Editor Mitchell S.V. Elkind, MD, MS

\title{
A woman with recurrent aphasia and visual field defects
}

Bardia Nourbakhsh, MD

Julio C. Rojas, MD, PhD

Chirantan Banerjee, MD, $\mathrm{MPH}$

Roberta L. Novakovic, MD

Worthy Warnack, MD

Correspondence to Dr. Warnack: worthy.warnack@utsouthwestern. edu
A 73-year-old woman with a history of hypertension and a recent stroke presented with recurrent nonsensical speech and visual problems. One month prior, she had been diagnosed with a stroke after suddenonset speech and visual difficulties that resolved after a few hours. Thirteen days before, she had had a second episode of similar symptoms. She was seen in our institution after a few hours of sudden-onset unintelligible speech. Her vital signs were within normal limits. She was not in distress but appeared frustrated. Her general physical examination was unremarkable. She had no carotid, ophthalmic, or cranial bruits. Her neurologic examination was notable for fluent aphasia with paraphasic errors and inability to name, read, or write. She also had right homonymous hemianopia, right-sided sensory loss, and generalized brisk deep tendon reflexes. The rest of her neurologic examination showed no abnormalities.

What is your differential diagnosis? What diagnostic modalities would you use to investigate the cause of her symptoms? This woman presented with recurrent acute-onset fluent aphasia, right homonymous hemianopia, and right-sided sensory loss. These findings localize to the cortical/subcortical areas in the left temporal and parietal lobes. In an elderly patient with a history of hypertension, an acute ischemic or hemorrhagic stroke is the most likely diagnosis. Other diagnostic possibilities include infections (e.g., herpetic encephalitis, abscesses), inflammation (a demyelinating lesion), primary or metastatic brain tumors, toxic-metabolic abnormalities, mitochondrial disorders, and seizures. She recovered completely from 2 similar transient episodes in the previous month. This narrows the differential diagnosis to TIA, seizures, metabolic abnormalities, migrainous phenomena, or a fixed lesion that becomes symptomatic in the setting of an infection or a metabolic abnormality.

Prompt neuroimaging and basic metabolic workup are the most important initial diagnostic modalities for this patient. A head non-contrast-enhanced CT (NECT) showed decreased attenuation and edema in the left temporal lobe (figure, A). There was no intraparenchymal or extra-axial hemorrhage. After 48 hours, her aphasia and right-sided sensory loss had resolved, but right homonymous hemianopia persisted.

Would have you treated this patient with IV thrombolysis? How could a fixed anatomic lesion in the left temporal lobe explain multiple transient episodes of neurologic deficits? In the setting of possible recent acute ischemic events and prominent hypodensity of the left temporal lobe on NECT, IV thrombolysis was considered contraindicated. Although the radiologic features of the temporal lobe lesion on the head NECT were suggestive of a subacute ischemic stroke, the pattern of edema and hypodensity was not characteristic of involvement of an arterial vascular distribution.

The presence of edema in the temporal lobe raised the possibility of herpetic encephalitis. However, the absence of fever, waxing and waning nature of symptoms (as opposed to rapidly progressing symptoms), and involvement of the lateral temporal lobe (rather than the medial part) argued against this diagnosis.

The transient episodes of aphasia could have also represented focal seizures. However, an EEG performed while the patient was still symptomatic showed only intermittent polymorphic delta slowing in the left temporal region without electrographic seizures.

Vasogenic edema causing transient neurologic dysfunction was an additional diagnostic possibility. Vasogenic edema is characteristic of mass lesions, including abscesses or neoplasia. However, edema and mass effect caused by tumors is usually progressive or fluctuating in symptoms when associated with seizures.

Cerebral venous sinus thrombosis (CVST) can present with focal neurologic deficits and hypodense lesions on the head NECT that do not conform to an arterial distribution, but fluctuation of symptoms and absence of headache and papilledema would be unusual in acute or subacute CVST.

A head CT angiogram (CTA) was notable for increased vascularity in the left posterior temporooccipital and left inferior temporal lobes. The radiologist reported that the evaluation was limited due to venous contamination (figure, B).

From the Department of Neurology \& Neurotherapeutics, University of Texas Southwestern Medical Center, Dallas.

Go to Neurology.org for full disclosures. Funding information and disclosures deemed relevant by the authors, if any, are provided at the end of the article. 

fistula

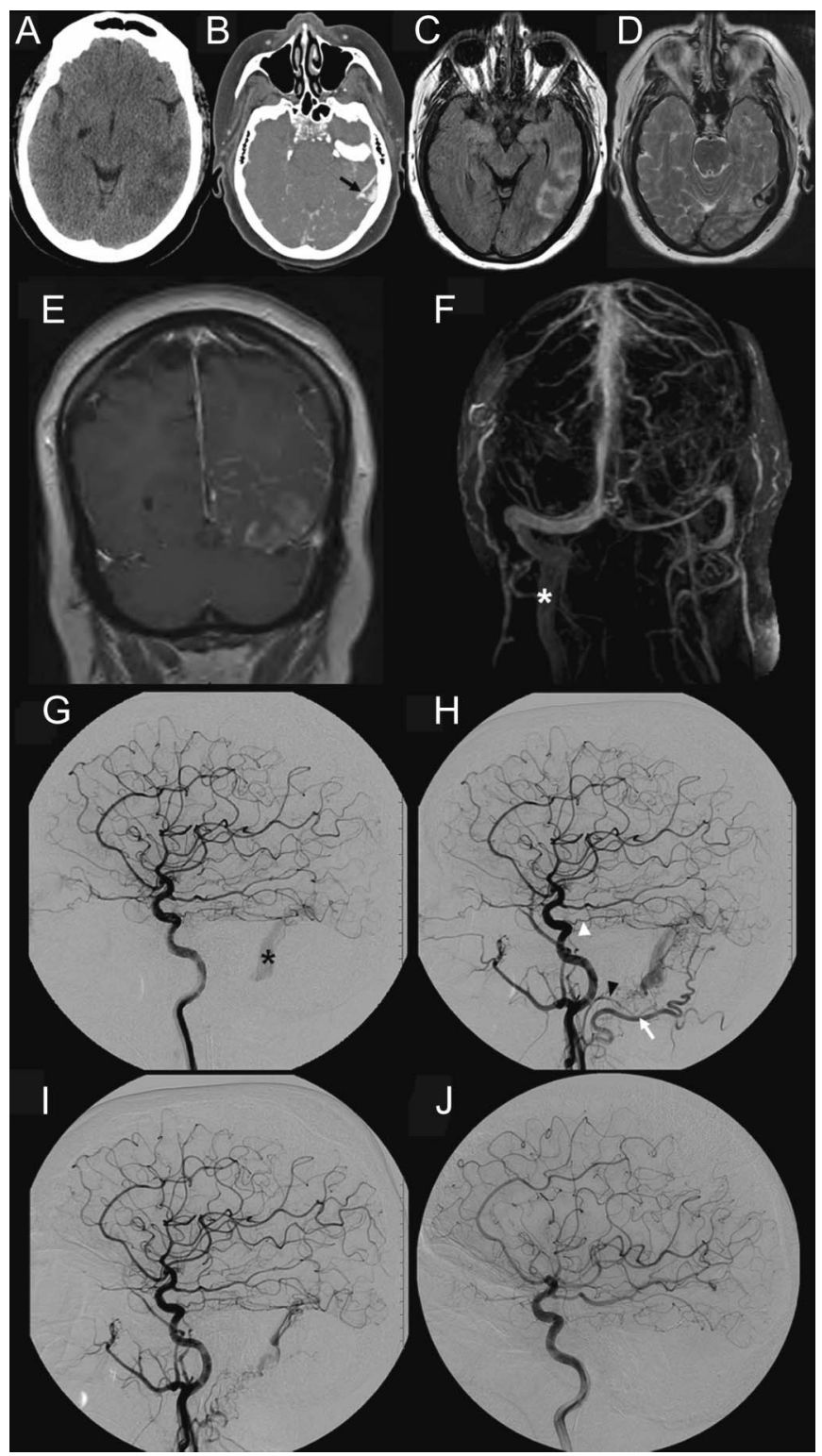

(A) Head non-contrast-enhanced CT shows left temporo-occipital sulcal effacement, edema, and mass effect on the occipital horn of the lateral ventricle. (B) Luxury perfusion or venous collaterals related to the transverse sinus (black arrow) appear as increased left temporo-occipital vascularity in head CT angiogram. (C) This area also shows a significant fluid-attenuated inversion recovery signal abnormality. (D) Brain MRI T2 sequence reveals an abnormal flow void in the left temporal lobe draining to the region of the left transverse sinus/sigmoid sinus junction. (E) Gadolinium-enhanced images show left temporal cortical extensive patchy serpiginous vascular enhancement. (F) In MRI brain venogram, the left internal jugular vein receives multiple collaterals and appears diminutive, compared to the right internal jugular vein (white asterisk). Whereas the left transverse and distal sigmoid sinuses also appear narrowed, the proximal left sigmoid sinus is prominent and receives an enlarged temporal vein. (G) An arterialized loculated outflow in the sigmoid sinus (black asterisk) is observed on digital subtraction images of a cerebral angiogram after left internal carotid artery contrast injection. $(\mathrm{H})$ The Cognard type llb dural arteriovenous fistula fills from en passage vessels from the left occipital artery (white arrow), middle meningeal artery, left meningohypophyseal trunk (white arrowhead), and the posterior division of the ascending pharyngeal arteries (black arrowhead). (I) Moderate delay in filling of the fistula was achieved after arterial embolization of a posterior division branch of the ascending pharyngeal and occipital arteries. Arterial contribution from an additional branch from the ascending pharyngeal artery, the meningohypophyseal trunk, and the distal middle meningeal branch remains. (J) A follow-up cerebral angiogram 3 months after a left retrosigmoid craniectomy for surgical obliteration of cortical veins and tributaries from the left meningohypophyseal trunk shows no evidence of residual arteriovenous fistula.
How would this information narrow your differential diagnosis? Luxury perfusion syndrome is a focal increase in cerebral blood flow accompanied by a reduction in cerebral oxygen extraction fraction. This phenomenon can be seen after an ischemic stroke and is thought to be secondary to tissue metabolic acidosis. ${ }^{1}$ Concomitant presence of increased vascularity and venous contamination on the CTA raised the possibility of an abnormal connection between the arterial and venous systems. Brain MRI with and without contrast, magnetic resonance (MR) angiography, and MR venography were obtained within 24 hours. There was no restricted diffusion, but there was a large area of T2 signal abnormality in the left temporal and occipital lobes and an abnormal flow void in the left temporal lobe draining into the left transverse/sigmoid sinus junction. Extensive vascular enhancement traversing through the left temporal, occipital, and parietal lobes was noted. MR venogram showed a prominent proximal left sigmoid sinus with an abnormally enlarged left temporal vein draining into it. The above findings were compatible with dural arteriovenous fistula (DAVF) (figure, C-F).

How does an intracranial DAVF present clinically? How are they managed? DAVF is an abnormal connection between the dural arteries or pachymeningeal branches of cerebral arteries and dural veins. The incidence of DAVF is reported as one-tenth of intraparenchymal arteriovenous malformations and they tend to present later in life. ${ }^{2}$ They are thought to be acquired lesions and the most common predisposing factor seems to be CVST, although head trauma, ear infection, and previous cranial surgery have been reported as potential underlying causes of DAVF. ${ }^{3}$ While the exact pathogenesis is unclear, venous hypertension due to venous thrombosis is thought to play a role. It promotes the release of angiogenic factors and opens up microscopic vascular connections within the dura. ${ }^{4}$ DAVF may remain clinically silent and involute spontaneously. ${ }^{5}$ The range of clinical symptoms varies widely and is highly dependent on the location of the fistula and the pattern of venous drainage. For example, a petrous region DAVF draining into transverse or sigmoid sinuses may produce pulsatile tinnitus, whereas an indirect carotid-cavernous sinus fistula can present with orbital signs and ophthalmoplegia. Acute confusional state, rapidly progressive dementia, parkinsonism, and periodic paralysis are reported as uncommon manifestations of DAVF. To our knowledge, only one case of DAVF presenting with sensory aphasia was previously reported in the literature. ${ }^{6}$ The most ominous presentation of DAVF is intracranial hemorrhage, but neurologic complications can occur in the setting of retrograde superficial cortical drainage. ${ }^{7}$ Focal neurologic deficits that occur without bleeding may be due 
to venous hypertension or arterial steal, while intermittent symptoms may occur through transient hyperemia, as opposed to transient ischemia. ${ }^{8}$ The Cognard system is commonly used to classify DAVF (table). ${ }^{9}$

Because of nonspecific clinical and radiographic features of DAVF, diagnosis is often delayed. There is no information regarding the sensitivity and specificity of different imaging modalities for DAVFs. In patients who present with neurologic deficits, NECT is usually abnormal, although the findings are nonspecific and include hemorrhage or parenchymal hypodensities. White matter changes from venous congestion and dilated cortical veins, if present, are easily discernible on conventional MRI sequences. Noninvasive vascular imaging usually provides the first hints about the presence of a DAVF, but if there is no cortical venous reflux, DAVF can be missed by both CTA and MRI. Regional cerebral blood flow is reduced in symptomatic patients with cortical venous drainage, which supports a role of perfusion studies in the prediction of DAVF complications. ${ }^{10}$ Conventional catheter angiography is the diagnostic procedure of choice to better define the arterial feeding vessels and venous outflow of the fistula.

In our patient, the MRI findings were suggestive of the presence of an intracranial DAVF. Her catheter angiogram showed a Cognard type IIb DAVF (figure, $\mathrm{G})$. Because of the high-risk features of the DAVF, including retrograde flow through superficial cerebral veins, cerebral edema, and recurrent neurologic deficits, treatment was deemed necessary. Endovascular, open surgical, and radiosurgical approaches have been used for treatment of DAVFs. In our case, venous embolization of the fistula was attempted; however, because the fistularized segment of the sinus was loculated and occluded proximal and distal to the segment catheterized, embolization could not be achieved. The presence of multiple small and tortuous arterial feeders made an arterial approach for embolization unsuccessful at complete obliteration (figure, $\mathrm{H}$ and I). At a later time, the patient underwent an open craniotomy with direct exposure of the sinus and

\begin{tabular}{|ll|}
\hline Table & The Cognard classification system of dural arteriovenous fistulae \\
\hline Type & Venous drainage \\
Type I & Normal anterograde flow with drainage into a venous sinus \\
Type II & Drainage into a venous sinus with retrograde flow: \\
& Ila: Within the sinus \\
& Ilb: Into cortical veins \\
Type III & Ila+b: Within the sinus and into the cortical veins \\
Type IV & Drainage into a cortical vein \\
Type V & Drainage into a cortical vein with venous ectasia \\
\end{tabular}

successful surgical transection of the cortical draining veins and the remaining feeding arteries to the fistula. She tolerated all these procedures well and aside from residual right homonymous hemianopia, she remained symptom-free. An angiogram obtained 3 months after presentation showed no evidence of remaining DAVF (figure, J).

This case illustrates that a vascular malformation can present with recurrent transient focal deficits. In rare circumstances such as this, there is no easy way to quickly identify patients with nonischemic causes of acute focal neurologic deficits and avoid unnecessary and potentially harmful thrombolysis. A welldefined hypodensity with increased vascularity is an uncommon early finding in acute ischemic stroke. In the setting of recurrent neurologic deficits, these findings should prompt a thorough neurovascular evaluation.

\section{AUTHOR CONTRIBUTIONS}

Dr. Bardia Nourbakhsh: drafting/revising the manuscript, study concept and design, acquisition of data, analysis and interpretation. Dr. Julio C. Rojas: drafting/revising the manuscript, acquisition of data, analysis and interpretation. Dr. Chirantan Banerjee: acquisition of data, analysis and interpretation. Dr. Roberta (Robin) Novakovic: critical revision of the manuscript. Dr. Worthy Warnack: study concept and design, critical revision of the manuscript for important intellectual content and supervision.

\section{STUDY FUNDING}

No targeted funding reported.

\section{DISCLOSURE}

The authors report no disclosures relevant to the manuscript. Go to Neurology.org for full disclosures.

\section{REFERENCES}

1. Spreafico G, Cammelli F, Gadola G, Freschi R, Zancaner F. Luxury perfusion syndrome in cerebral vascular disease evaluated with technetium-99m HM-PAO. Clin Nucl Med 1987;3:217-218.

2. Newton TH, Cronqvist S. Involvement of dural arteries in intracranial arteriovenous malformations. Radiology 1969; 5:1071-1078.

3. Kwon BJ, Han MH, Kang HS, Chang KH. MR imaging findings of intracranial dural arteriovenous fistulas: relations with venous drainage patterns. AJNR Am J Neuroradiol 2005;10:2500-2507.

4. Uranishi R, Nakase H, Sakaki T. Expression of angiogenic growth factors in dural arteriovenous fistula. J Neurosurg 1999;5:781-786.

5. Luciani A, Houdart E, Mounayer C, Saint Maurice JP, Merland JJ. Spontaneous closure of dural arteriovenous fistulas: report of three cases and review of the literature. AJNR Am J Neuroradiol 2001;5:992-996.

6. Chou CH, Lin JC, Hsueh CJ, Peng GS. A thrombophilic patient with a dural arteriovenous fistula presenting sensory aphasia and complicated with an acute pulmonary embolism. Neurologist 2008;5:327-329.

7. Satomi J, van Dijk JM, Terbrugge KG, Willinsky RA, Wallace MC. Benign cranial dural arteriovenous fistulas: 
outcome of conservative management based on the natural history of the lesion. J Neurosurg 2002;4:767-770.

8. Lasjaunias P, Chiu M, ter Brugge K, Tolia A, Hurth M, Bernstein M. Neurological manifestations of intracranial dural arteriovenous malformations. J Neurosurg 1986;5:724-730.

9. Cognard C, Gobin YP, Pierot L, et al. Cerebral dural arteriovenous fistulas: clinical and angiographic correlation with a revised classification of venous drainage. Radiology 1995;3:671-680.

10. Iwama T, Hashimoto N, Takagi Y, et al. Hemodynamic and metabolic disturbances in patients with intracranial dural arteriovenous fistulas: positron emission tomography evaluation before and after treatment. J Neurosurg 1997; 86:806-811. 


\section{Neurology}

\section{Clinical Reasoning: A woman with recurrent aphasia and visual field defects}

Bardia Nourbakhsh, Julio C. Rojas, Chirantan Banerjee, et al.

Neurology 2013;81;e141-e144

DOI 10.1212/01.wnl.0000435292.57221.a7

This information is current as of November 4, 2013

\section{Updated Information \&} Services

References

Subspecialty Collections

Permissions \& Licensing

Reprints including high resolution figures, can be found at: http://n.neurology.org/content/81/19/e141.full

This article cites 10 articles, 0 of which you can access for free at: http://n.neurology.org/content/81/19/e141.full\#ref-list-1

This article, along with others on similar topics, appears in the following collection(s):

All Cerebrovascular disease/Stroke

http://n.neurology.org/cgi/collection/all_cerebrovascular_disease_strok e

Aphasia

http://n.neurology.org/cgi/collection/aphasia

Other cerebrovascular disease/ Stroke

http://n.neurology.org/cgi/collection/other_cerebrovascular_disease_s troke

Information about reproducing this article in parts (figures,tables) or in its entirety can be found online at:

http://www.neurology.org/about/about_the_journal\#permissions

Information about ordering reprints can be found online:

http://n.neurology.org/subscribers/advertise

Neurology ${ }^{\circledR}$ is the official journal of the American Academy of Neurology. Published continuously since 1951, it is now a weekly with 48 issues per year. Copyright () 2013 American Academy of Neurology. All rights reserved. Print ISSN: 0028-3878. Online ISSN: 1526-632X.

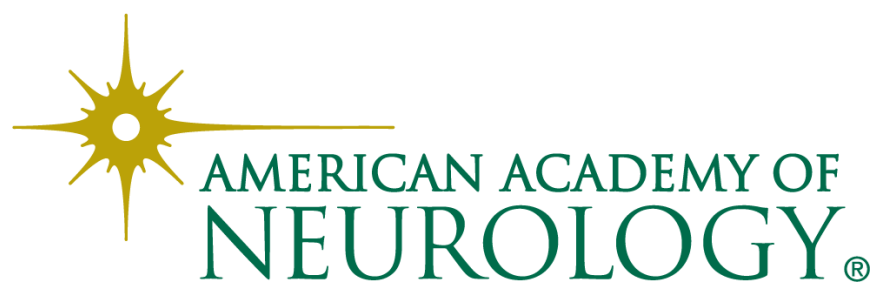

